\title{
DEVELOPMENT OF WOP MATHEMATICAL MODEL FOR OPTIMUM TRACK-KEEPING. A SHIP SIMULATION STUDY USING VLCC, FOCUSING ON HARD OVER RUDDER TURNING CIRCLE WITH THREE STAGES OF VALIDATION ANALYSIS
}

\author{
Amir Syawal Kamis * 1 \\ Ahmad Faizal Ahmad Fuad ${ }^{3}$ \\ Azmirul Ashaari ${ }^{2}$ \\ Che Wan Mohd Noor ${ }^{3}$ \\ Sheikh Alif Ali ${ }^{3}$ \\ ${ }^{1}$ Akademi Laut Malaysia, Malaysia \\ ${ }^{2}$ Universiti Teknologi Malaysia, Malaysia \\ ${ }^{3}$ Universiti Malaysia Terengganu, Malaysia \\ *Corresponding author: amirsyawal87@gmail.com (A.S. Kamis)
}

\begin{abstract}
Navigational safety necessitates careful route monitoring, which includes staying on the planned course. For a ship to achieve effective route monitoring while changing course, a wheel over point (WOP) must be precisely calculated and marked on a charted course. The reason is to warn the watchkeeping officer that the ship must make a course alteration to prevent overshooting the intended route. One of the techniques for appraising the WOP is the advance transfer technique (ATT). During a practical review by means of an electronic and paper chart work exercise of the $A T T$, this study discovered two research gaps related to the technique. Following that, this study created an improved advance transfer mathematical model (ATMM) by restructuring the use of the ship's turning circle to overcome the limitations discovered. To validate the improvement of the ATMM over the ATT, data were collected by evaluating both methods using a ship simulator and performing a manoeuvring analysis. The data, specifically the reduction in the cross-track distance (XTD), was validated in three verification stages: compliance with XTL, percentage change, and Mann-Whitney U test using IBM SPSS. In comparison to the ATT, the ATMM produces better results in terms of the course-keeping capability and it can be implemented as an algorithm in an integrated bridge navigation system for autonomous ship navigation safety.
\end{abstract}

Keywords: wheel over point, course alteration, mathematical model, passage planning, navigation safety

\section{BACKGROUND OF STUDY}

The primary function of commercial shipping is to transport freight to its destination safely. According to ICS (2018), the shipping industry facilitates $90 \%$ of global trade, which consists of liquid, bulk, and gas cargoes. The overall volume of the annual global maritime exchange had surpassed 14 trillion US dollars as of 2019. However, shipping is one of the world's most dangerous professions due to its nature of transportation.

Fig. 1 outlines the context of this topic's selection. Seafaring is a high-risk career due to the unpredictability of the work on board the ship, which can result in injuries, sickness, or even fatalities [1]. As a result, any operation on board the ship necessitates careful preparation, planning, execution, and monitoring to ensure shipboard safety [2]. Shipboard safety is described as the approach of performing operations on board a ship in a secure manner that involves the cargo's safety, the safe operation of its machinery, the safety of navigation, and the safety of the ship's crew.

One of the essential operations on board a merchant vessel is to navigate the ship safely. To ensure navigation safety is heightened, the officer in charge of the navigational watch must be skilled in maintaining safe navigation, besides 
knowing how to respond to shipboard emergency and distress signals, as part of the required competency [3]. Aside from that, the officer must communicate effectively, navigate the ship and, most notably, carry out a voyage plan [3].

The phrase „passage planning” or „voyage planning” refers to the process of creating a detailed plan of a ship's journey [4]. According to IMO resolutions A.893 (21), there are four phases of the passage plan. In the appraisal stage information is collected, which includes the weather, communication with the authorities, charts and publications, and many other types of information that can be used to ensure the safety of the ship during the voyage from the departure port to the arrival port. With all the collected information, the navigational officer will begin charting the course line and preparing the ECDIS passage. The passage plan will then be carried out and tracked according to the approved plan. Monitoring a passage entails keeping an eye on the weather forecast, taking appropriate precautions to prevent a collision, and ensuring the ship stays on track [4].

The charted course line has been calculated to be the safest route. Consequently, remaining on the charted course, also known as track-keeping, is crucial in navigation. However, depending on the circumstances and conditions, it might be necessary to deviate from the intended route [5]. Any effort to deviate from the route would be deemed risky at first. If necessary, an extra assessment of the current path must be done to carry out the course deviation. Optimum track-keeping can be accomplished using autopilot or manual steering [6]. Nonetheless, both approaches necessitate careful observation of the cross-track distance (XTD) expansion.

The perpendicular distance between the vessel and the expected track is defined as the XTD [7]. The watchkeeping officer will change the ship's heading if needed to ensure that the ship's direction matches the charted course. This intervention will keep the ship on course and prevent the XTD from developing. However, sometimes, due to a late course change, the ship will overshoot from the track, resulting in a cross-track distance, as seen in Fig. 2 [8], [9]. As a result, a wheel over point (WOP) must be measured precisely in advance and labelled on the charted course to denote the point of change [4]. A lack of knowledge of how to calculate the WOP will result in route overshooting and possibly a severe accident.

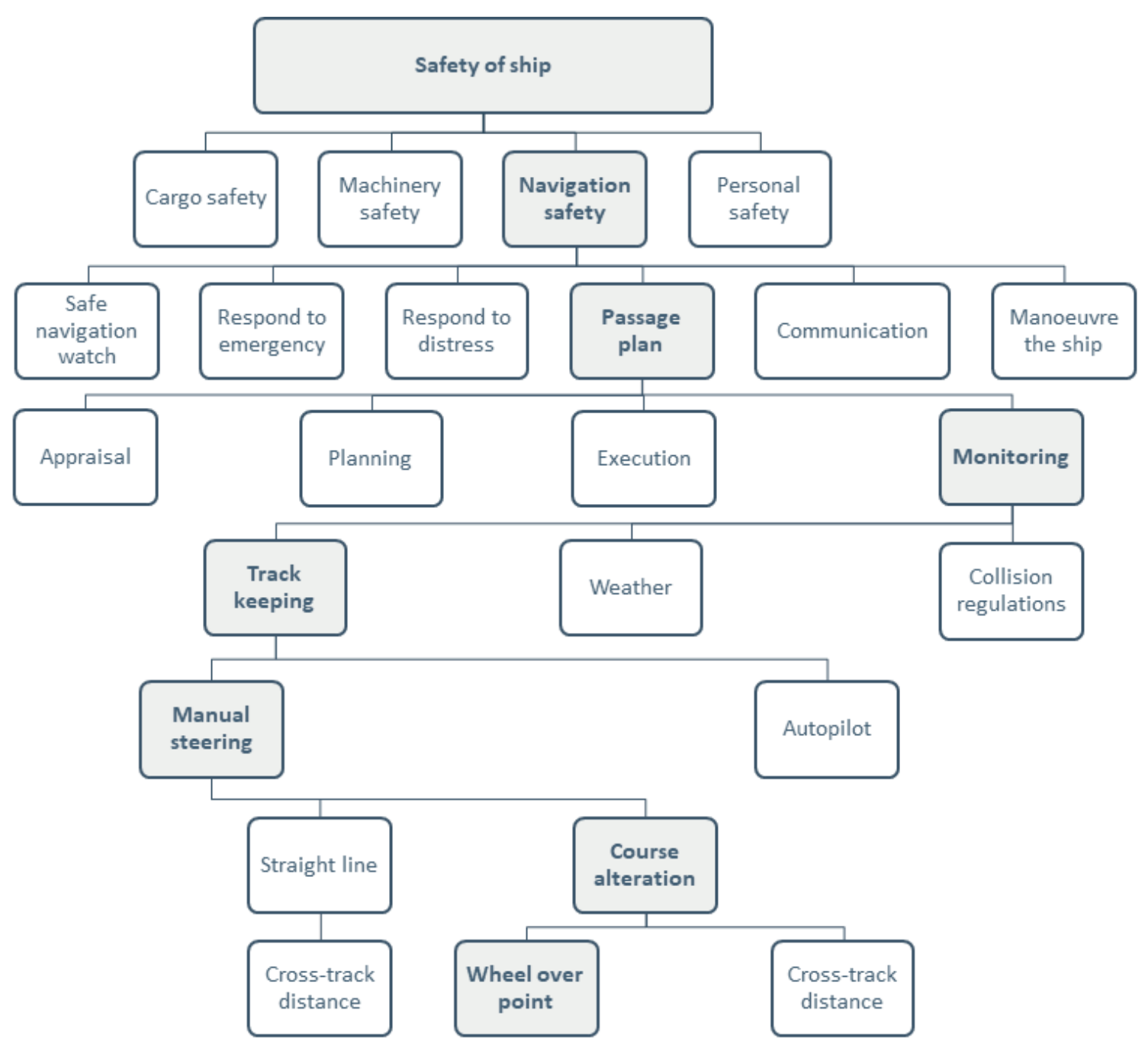

Fig. 1. Research background K-Chart 


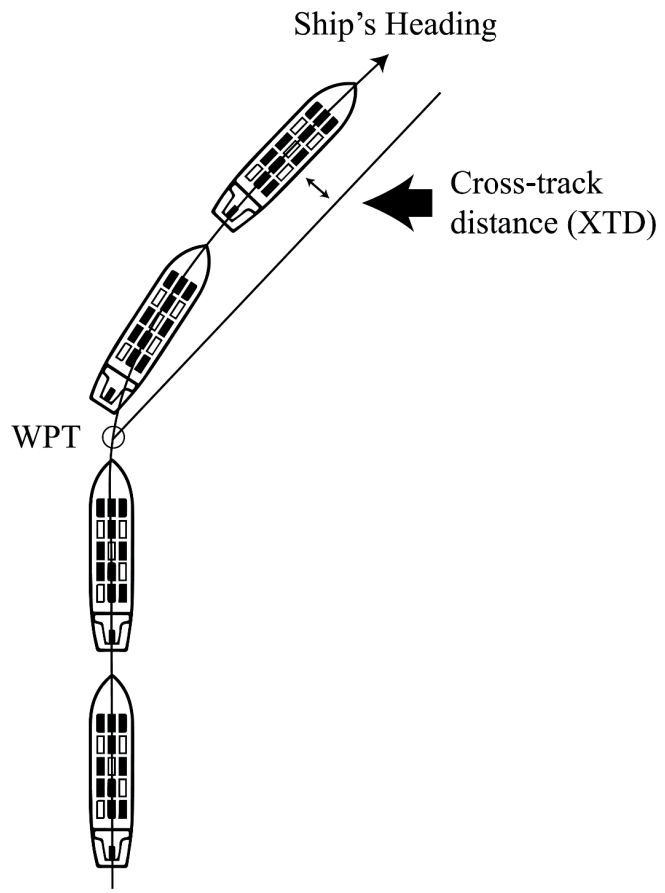

Fig. 2. Development of XTD due to overshooting the planned course

\section{LITERATURE REVIEW}

\section{WHEEL OVER POINT}

\section{A Reminder to the Navigation Officer}

The WOP refers to the point on the plotted course that serves as a reminder to the navigation officer to commence the course alteration so that the ship does not deviate from the intended course [10]. The WOP may help to reduce fuel usage by optimising the vessel's voyage by keeping an optimal path [11]-[13]. Most significantly, it makes a substantial contribution to the ship's navigational safety [9]. Inadequate understanding of the ship's turning capability and manoeuvrability may result in a major catastrophe [14]. Previous studies by the Transport Accident Investigation Commission (TAIC), the Marine Accident Investigation Branch (MAIB), and the Australian Transport Safety Bureau indicated that failing to establish the WOP resulted in navigation accidents [14]-[16].

\section{A Point for Monitoring Pilot Behaviour}

Apart from that, the WOP can be utilised to monitor the pilot's judgement. For decades, there have been numerous accidents involving pilotage [17]; for example, vessels have run aground due to the pilot sleeping [18], making a late course correction [19], making a judgement error [20], making an insufficient course correction [21], making an insufficient turn [22], repeatedly overshooting a planned track [23], and lacking knowledge with regard to natural effects [24]. Between
2004 and 2013, in Korea, 47 maritime mishaps occurred during pilotage [25].

The instances highlighted were of accidents that occurred as a result of human error. Human error is notoriously difficult to anticipate [26]; nevertheless, with the WOP highlighted on the chart, it can be utilised to track the occurrence of human error, specifically during turning. In this instance, the pilot's behaviour may be anticipated by observing his actions throughout a turn. If the pilot modifies the course before the WOP, the master will have confidence in the pilot's judgement. On the other hand, if the pilot carries out the course alteration after the WOP, the master or navigation officer may interfere and overrule the pilot's authority [27]. However, if the WOP is not properly established, monitoring becomes problematic, since the master will have no way of knowing whether or not the pilot has made a judgement mistake [28], [29]. As a result, it is critical to establish an exact location for the WOP [4], [30]. Even those who are highly skilled and competent may lack situational awareness, have inaccurate judgement, or be unfamiliar with novel circumstances. Additionally, individuals may be overburdened with many duties or issues during a crisis which goes beyond their ability to cope with novel circumstances. As a result, the navigation officer and the ship's master must create a procedure for verifying the pilot's judgement [31].

\section{ROUTE MONITORING BY ECDIS}

The Electronic Chart Display Information System (ECDIS) and the Electronic Navigation Chart (ENC), which are connected to the Integrated Bridge Navigation System (IBNS) through an improved interface, have helped navigation officers considerably in route monitoring [32] data reliability, alarm management and ship's safety parameter settings. For the optimum situational awareness, navigators must always recognize the level of display for objects presented when using ECDIS. The values for the safety depth and safety contour must be understood and entered to achieve a sensible and considered meaning and alarm settings. The navigators must remember that the display of underwater obstructions or isolated danger symbols can change according to the settings of this safety contour which also marks the division between navigable (safe. However, not all vessels are presently equipped with ECDIS or ENC, since the technology is only required for passenger ships above $500 \mathrm{gt}$ and cargo ships over $3000 \mathrm{gt}$ in accordance with SOLAS regulations V/19 [33], [34]. As a result, the remaining sailors continue to manoeuvre using their repertoire of conventional navigation abilities [35]. This statement is strengthened by the study conducted by Wu et al. such as Radar/ARPA, Automatic Identification System (AIS[36]such as Radar/ARPA, Automatic Identification System (AIS, where it was found that fourteen out of sixteen sailors preferred to use traditional navigation methods in addition to technology while maintaining a safe watch, highlighting the need for preserving traditional navigation abilities. 


\section{CONSTANT RADIUS TURN}

The constant radius turn (CRT) technique calculates the rate of turn (ROT) required for a fixed radius turn [9], [11], [37], [38]. The technique requires a rate of turn indicator (ROTI), which is a navigation instrument used to indicate the ship's turning rate in degrees per minute and designed to observe the turning rate [38]. The ROT, given in degrees per minute, must be agreed upon collectively by the bridge team in advance during the 'appraisal' stage in order to plan the WOP in accordance with the navigator's suitability and the master's orders [10]. Additionally, this method is dependent on the helmsman's skills to control the rudder angle in such a way that the ROT remains constant and does not vary much throughout the turning time. The formula to calculate the WOP using the CRT is as follows [39]:

$$
W O P=\frac{57.3 \times V}{60 \times R O T}(1-\cos \theta)+F \sin \theta
$$

where the ROT is the value agreed by the bridge team, $\mathrm{V}$ is the speed of the vessel at the time of execution in knots, $\theta$ is the turning angle to be executed in degrees $\left(^{\circ}\right)$, and $\mathrm{F}$ is the ship's length in nautical miles.

\section{CONSTANT RATE OF TURN}

The constant rate of turn (CROT) is another technique used to calculate the WOP according to the ship's speed and the agreed rate of turn (ROT). This approach also necessitates the use of a rate of turn indicator (ROTI) to keep track of the turning rate [38]. This technique also requires the helmsman's experience in controlling the rudder. The formula for the CROT is given as follows:

$$
W O P=\frac{\Theta \cdot V \cdot 0.5}{60 \times R O T}+F
$$

where the ROT is the value agreed upon by the bridge team. $\mathrm{V}$ is the speed of the vessel at the time of execution in knots. $\theta$ is the turning angle to be executed in degrees $\left(^{\circ}\right)$ and $\mathrm{F}$ is the ship's length in nautical miles. The distance of the WOP measured from the WPT, which is obtained through the calculation, needs to be marked on the charted course.

\section{ADVANCE TRANSFER TECHNIQUE (ATT)}

The manoeuvring characteristic of a vessel is subject to the rudder angle ordered for a particular manoeuvre [40]. A constant turning circle can be achieved by fixing the ship's rudder at a certain angle [41]. On the day the ship is launched, a sea trial manoeuvre will be carried out, which provides the specific manoeuvring characteristic for that ship. Manoeuvring details are recorded, including a turning circle for every particular rudder angle [42]. This method of fixing the rudder at a hard over rudder angle during turning is also known as the advance transfer technique (ATT) [10].

\section{ATT first advantage - Can be calculated during planning stages}

The CRT and CROT incorporate the vessel's speed (V) and rate of turn (ROT) into their respective formulae as seen in equations (i) and (ii) [39]. The ATT, on the other hand, enables the calculation of the WOP without needing to take the ship's speed and ROT into account, as shown later in equation (2), since the turning circle's characteristic is unaffected by the vessel's speed [40].

In open sea navigation, a ship's speed may be assumed to be constant and predictable in relation to its prior voyage service speed. Thus, the CRT and CROT methods are applicable in such a situation.

In comparison, the ship's speed is often changed in inland water based on traffic congestion, visibility, water depth, manoeuvrability, navigation hazards [5], and as per the pilot's advice [43]. As mentioned earlier, the ROT must be established prior to voyage planning to calculate the WOP using the CRT and CROT. However, without knowing the ROT that is going to be used by the pilot, it is impossible to carry out the calculation. As a result, the CRT and CROT are difficult to calculate during the planning stage in a voyage plan for navigation in inland water and pilotage. Consequently, the ATT is preferred during the planning stages, while the CRT and CROT can be utilised later once the speed and ROT are known during the monitoring stages during pilotage.

\section{ATT second advantage - Maximum rudder angle}

Another advantage of the ATT is that the WOP value obtained is calculated based on the maximum rudder angle, which implies that the WOP produced will be the final point to take action, whereas the CRT and CROT can be calculated based on any rate of turn depending on the navigator's suitability. If the WOP is calculated based on a small ROT such as $10 \% \mathrm{~min}$, it will result in a larger WOP value compared to $20 \% \mathrm{~min}$. Therefore, the ATT is suitable to use as the final point to monitor the pilot's decision. 


\section{APPLICATION OF ADVANCE TRANSFER TECHNIQUE} (ATT)

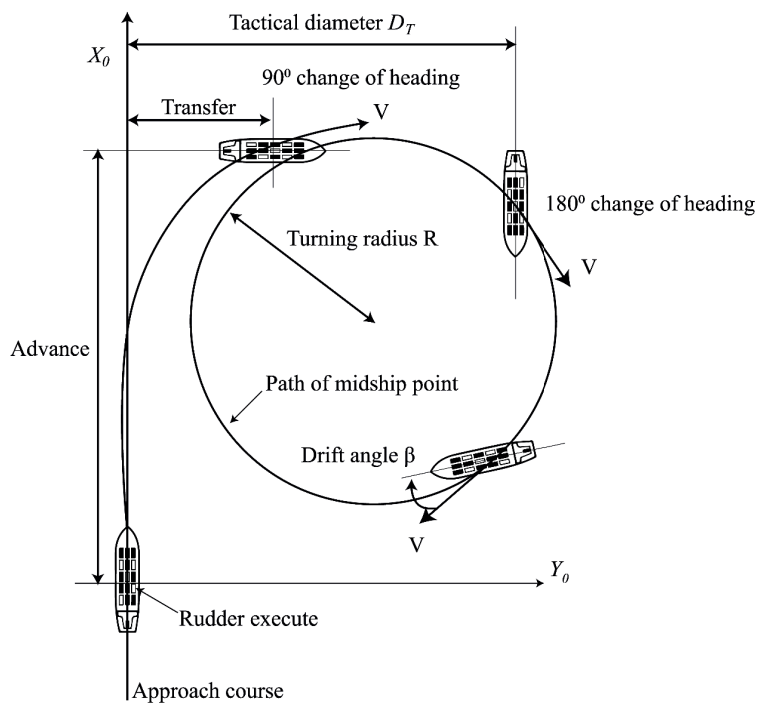

Fig. 3. Typical manoeuvring characteristic of a ship [42]

The ATT requires two items of information to be extracted from the manoeuvring characteristic, as shown in Fig. 3, namely the 1) advance and 2) transfer distance, hence its name. The advance and transfer distances are measured by referring to the positioning of the ship's centre of gravity (CG) and are measured from the moment the vessel initiates the turn by hard over the rudder until the ship's course changes by $90^{\circ}$ from the initial heading, where the distance of advance is on the $\mathrm{X}_{0}$ axis, and the distance of transfer is on the $\mathrm{Y}_{0}$ axis as shown in Fig. 3 [44]. The advance and transfer distances are usually expressed in nautical miles $(\mathrm{nm})$. The technique is further explained as follows.

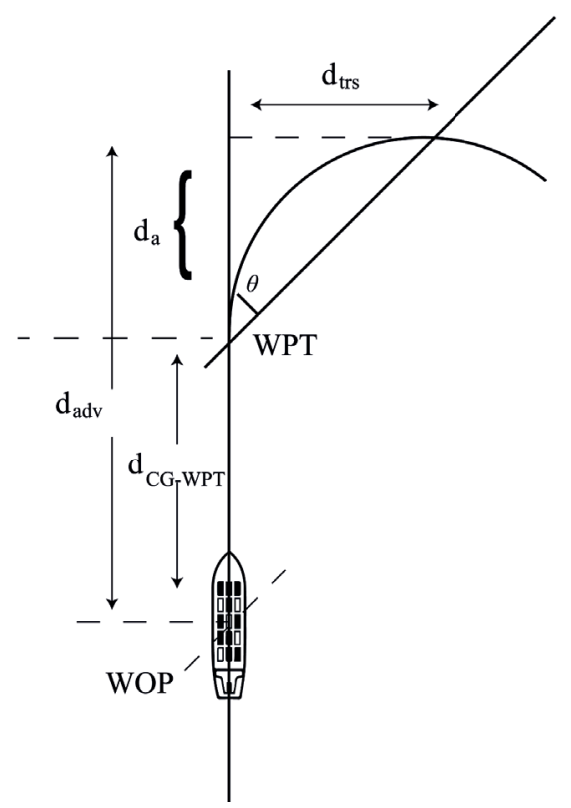

Fig. 4. Marking WOP [10]
With reference to Fig. 3 and 4, the terms used for explaining the formula are as follows:

$d_{a d v} \quad=$ Advance distance taken from manoeuvring characteristic

$d_{\text {trs }}=$ Transfer distance taken from manoeuvring characteristic

$d_{C G-W P T}=$ Distance from ship's centre of gravity to waypoint (WPT)

Based on the understanding of the technical concept shown in Fig. 4, the formula to calculate the WOP can be constructed. The angle of course alteration will be represented as $\theta$. The WOP, as defined by Anwar (2015), is the distance from the ship's centre of gravity (CG) to the WPT; thus, it will be named $d_{C G-W P T^{*}}$ To obtain $d_{C G-W P T}$, the advance distance, $d_{a d v}$, needs to be subtracted with $d_{a}$, therefore:

$$
d_{C G-W P T}=d_{a d v}-d_{a}
$$

$d_{a}$ can be obtained by utilising the tangent rule as follows:

$$
\begin{gathered}
\tan \theta=\frac{d_{t r s}}{d_{a}} \\
d_{a}=\frac{d_{\operatorname{trs}}}{\tan \theta}
\end{gathered}
$$

Hence, the formula of the advance transfer technique [10] is obtained as below:

$$
d_{C G-W P T}=d_{a d v}-\frac{d_{t r s}}{\tan \theta}
$$

\section{THE PROBLEM STATEMENT}

With the understanding of the ATT, a practical chartwork review on the technique was carried out in this research. However, referring to the formula given in (2), two main issues were found while carrying out the chartwork session, which are as follows.

\section{The first observation - Negative value for alteration less than $20^{\circ}$}

When the formula was used to identify the WOP for a vessel with an advance distance of $0.362 \mathrm{~nm}$ and a transfer distance of $0.169 \mathrm{~nm}$, the following results were obtained:

Tab. 1.WOP distance from WPT

\begin{tabular}{|c|c|c|c|c|}
\hline Situation & Change of course & $d_{a d v}$ & $d_{t r s}$ & $d_{C G-W P T}$ \\
\hline 1 & $20^{\circ}$ & 0.362 & 0.169 & -0.100 \\
\hline 2 & $50^{\circ}$ & 0.362 & 0.169 & 0.221 \\
\hline
\end{tabular}

A negative value of the WOP in situation 1 in Table 1 implies that the ship has to make the course alteration at $0.100 \mathrm{~nm}$ after the WPT, which means that the ship has overshot the planned track. Therefore, if this formula were 
to be used in an automated manoeuvring system algorithm, the calculated WOP would force the ship to overshoot the planned track.

\section{Second observation - The final heading of the ship does} not match the charted course

The technique's operating concept can be seen in Fig. 5. It can be seen that the ship's final course is $090^{\circ} \mathrm{T}$, which is different from the desired route of $045^{\circ} \mathrm{T}$. The formula will be more useful if the ship's final heading matches the desired charted direction, thus avoiding the second overshoot.

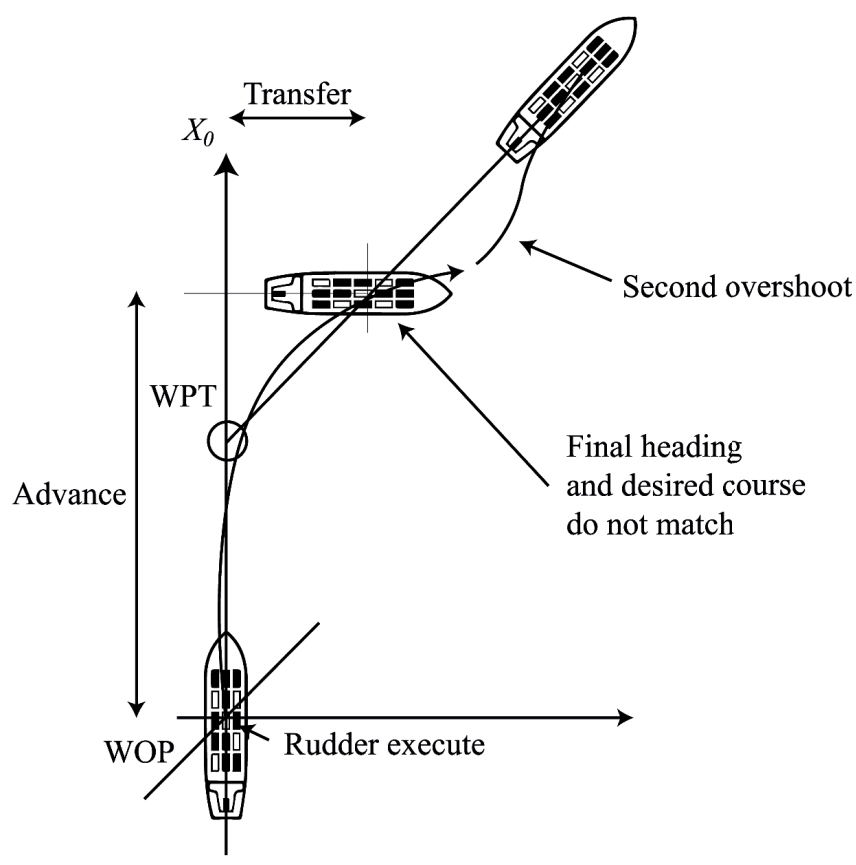

Fig. 5. Advance transfer technique principle

\section{RESEARCH AIM}

Hence, based on the observations and review, the following situations were identified;

1. The ATT is not suitable for a course alteration of less than $20^{\circ}$ as it will result in a negative value. A ship will start to make a course alteration after the WPT.

2. The ship's final heading and the charted course are contrary.

Since an Electronic Chart Display and Information System (ECDIS) is currently preferred in maritime navigation, mathematical modelling will be a more appropriate approach in determining the WOP. However, the formula provided by Anwar (2015) in the advance and transfer technique cannot be applied in the electronic chart due to the negative value produced for alteration less than $20^{\circ}$. Therefore, this research intends to restructure and develop an advance transfer mathematical model (ATMM) that may solve the problems.

\section{METHODOLOGY}

The research methodology's workflow is illustrated in Fig. 6.

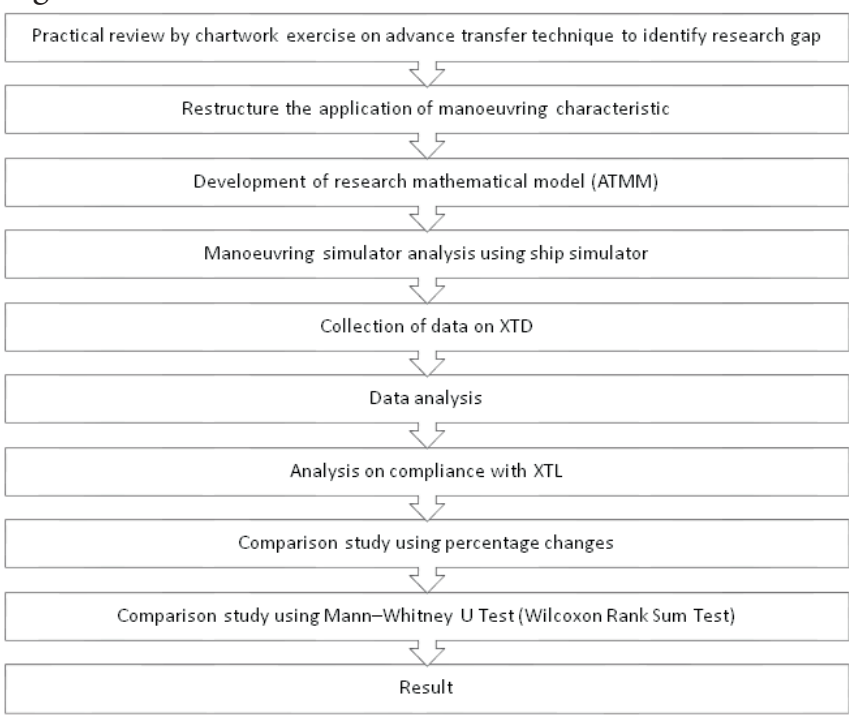

Fig. 6. Research methodology flow

The research started with a practical review carried out by the authors. The practical exercise of the advance transfer technique (ATT) using a ship simulator was aimed to further understand the research gaps, using electronic and paper charts. Once the research gaps were identified, then the research improvised the concept of determining the WOP by restructuring the turning circle application. From there, a new advance transfer mathematical model (ATMM) was established. According to Voit [45], a newly developed system needs to be tested against observations from the physical system which it represents. In this case, both the ATT and ATMM were tested using a ship simulator. This process is usually called validation [45].

During the full-scale simulation, data collection was carried out using the Wartsila ship simulator.

In this study, a very large crude carrier (VLCC) with a displacement of 63430 tons during the ballast condition and 159584 tons displacement during the laden condition will be used in the simulator analysis to verify the effectiveness of the developed mathematical model.

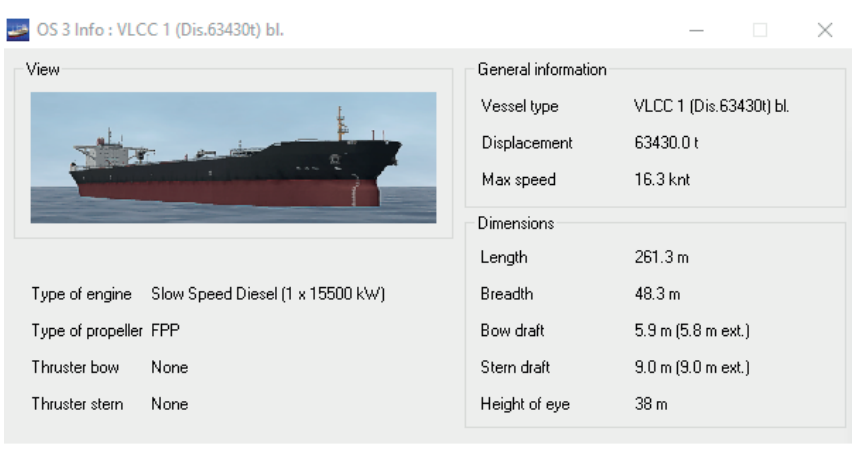

Fig. 7. VLCC general information on ballast condition taken from Wartsila simulator 


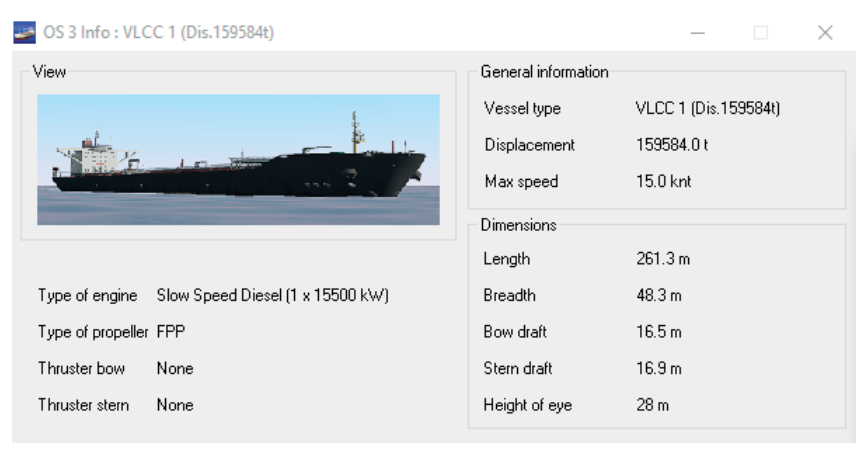

Fig. 8. VLCC general information on loaded condition taken from Wartsila simulator the data was analysed by comparing the XTD results from the ATT and ATMM with the requirements of the XTL as specified by the International Maritime Organisation [47] and following the guidance given by Kristić et al. (2020) [48]. This stage's purpose was to determine which method produced better compliance with the international or national regulations, which was defined by the XTL. The XTL is the limit whereby a ship can safely deviate from track. Even though the compliance with the XTL is expressed in general by IMO [7], the value of the XTL is not explored in detail. For this reason, this study used the guideline provided by Kristić et al. (2020) to determine the XTL.

During the second stage, to ensure that the system can provide continuous improvement, this study had chosen the

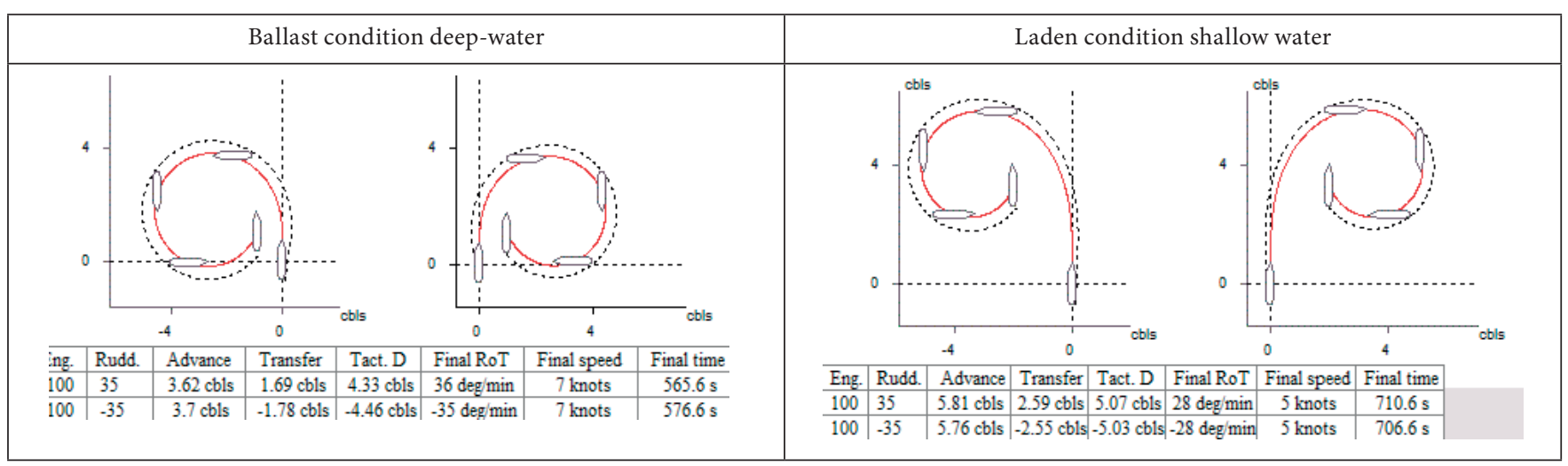

Fig. 9. The ship's deep and shallow water turning circle during ballast and loaded conditions

The data regarding the chosen ship shown in Fig. 7, 8 and 9 were obtained from the ship simulator.

Initially, a series of courses were constructed in an ECDIS simulator for a manoeuvring analysis. Both the ATT and ATMM were tested during the manoeuvring analysis. The data, mainly the XTD that was produced, were collected and documented in a table. The data on the XTD was collected because when two models of the same system are available, the researcher may want to compare them to choose one for future use, as in this case with the ATT and ATMM [45]. Therefore, the collected XTD data were compared to validate the improvement of the ATMM over the ATT.

In measuring the efficiency of the ATMM over the ATT, this study has considered and chosen the validation analysis which can comply with the requirements set by IMO [46]. According to IMO, whenever a new safety system is to be developed, the following requirements shall be taken into account [46]:

i. The system shall comply with the mandatory rules and regulations.

ii. The system can provide continuous improvement to safety management.

Accordingly, to fulfil the above requirements, the manoeuvring simulation data was analysed in three stages. During the first stage of analysis, to ensure that the developed ATMM complied with the mandatory rules and regulations, percentage change validation. To prove that the ATMM is an improved version of the ATT, the developed ATMM must reduce the XTD. The reduction of the XTD can be justified by adapting the method of identifying the percentage change as practised by Bansilal (2017)but not much is known about the ways in which students engage with contextual settings such as inflation. This qualitative study was conducted with in-service Mathematical Literacy teachers in South Africa with the purpose of exploring the extent to which the teachers recognised the contextual constraints involved in applying the percentage change calculation to the inflation context. The written responses of the 406 Mathematical Literacy teachers were scrutinised to identify their interpretations of the contextual constraints involved in applying the percentage change procedure to the context of inflation. The item required the application of two successive percentage change operations (corresponding to the inflation rates for the 2 years. The percentage change is a primary term that indicates the magnitude of the change over time. It is used for many financial purposes, primarily to reflect the shift in prices [49], [50]but not much is known about the ways in which students engage with contextual settings such as inflation. This qualitative study was conducted with in-service Mathematical Literacy teachers in South Africa with the purpose of exploring the extent to which the teachers recognised the contextual constraints involved in applying the percentage change calculation to the inflation context. The written responses of the 406 Mathematical Literacy teachers were scrutinised to identify their interpretations 
of the contextual constraints involved in applying the percentage change procedure to the context of inflation. The item required the application of two successive percentage change operations (corresponding to the inflation rates for the 2 years. Similarly, for this study, the percentage change was used to show the tendency of the ATMM in reducing the XTD compared to the ATT.

Then, in the final validation stage, the Mann-Whitney $U$ test was used to determine the effectiveness of the ATMM. This is a test to check whether one of the two random variables is stochastically larger than the other and it compares two independent groups that do not require large, normally distributed samples [51]particularly when conducting research in psychology, to have access to large normally distributed samples. Fortunately, there are statistical tests to compare two independent groups that do not require large normally distributed samples. The Mann-Whitney $U$ is one of these tests. In the following work, a summary of this test is presented. The explanation of the logic underlying this test and its application are presented. Moreover, the forces and weaknesses of the Mann-Whitney U are mentioned. One major limit of the Mann-Whitney $U$ is that the type I error or alpha ( $\alpha$. The Mann-Whitney or Wilcoxon-Mann-Whitney test is sometimes used for comparing the efficacy of two treatments in clinical trials [52]wilt, stalk and tuber rots diseases lead to considerable decline in Jerusalem artichoke (JA. All three tests demonstrated that the ATMM developed is better than the ATT in determining the WOP.

\section{RESTRUCTURE THE APPLICATION OF MANOEUVRING CHARACTERISTIC}

To improve the use of the advance and transfer distances in determining the WOP, this study intends to improvise the ATT technique so that the ship's final course matches the charted course in the passage plan.

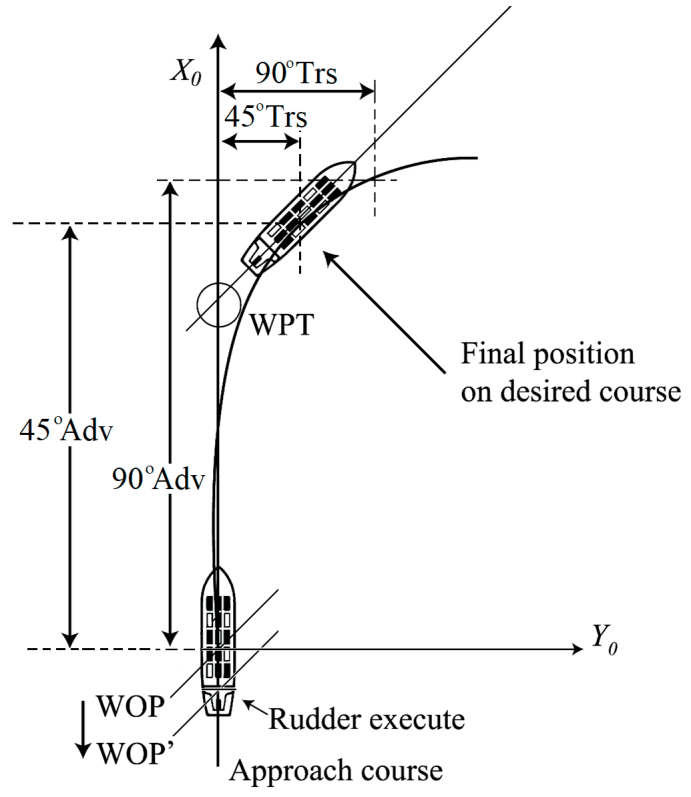

Fig. 10. This study's concept (ship's heading and course are the same at the end of course alteration)
To match the final course with the ship's heading, this research intends to redesign the technique as shown in Fig. 10 because the advance and transfer distances increase accordingly as the heading angle increases. As seen in Fig. 10, $d_{a d v}$ and $d_{t r s}$ for $45^{\circ}$ are required for the calculation. However, most ships are only provided with $d_{a d v}$ and $d_{\text {trs }}$ for $90^{\circ}$ [42]. Therefore, in this research, the positioning of the WOP was moved over to WOP'. For this reason, the following symbol is considered:

$$
d_{W O P^{\prime}}=\text { Distance of WOP' from WPT }
$$

\section{DEVELOPMENT OF RESEARCH MATHEMATICAL MODEL (ATMM)}

The mathematical model can be constructed from the existing equation that was published in the related study [45]. Therefore, the ATT formula by Anwar (2015) can be used as the groundwork of the new mathematical model. Fig. 11 is structured according to the generic diagram of a ship's turning circle. It will be used to assist in the explanation of the development of the ATMM.

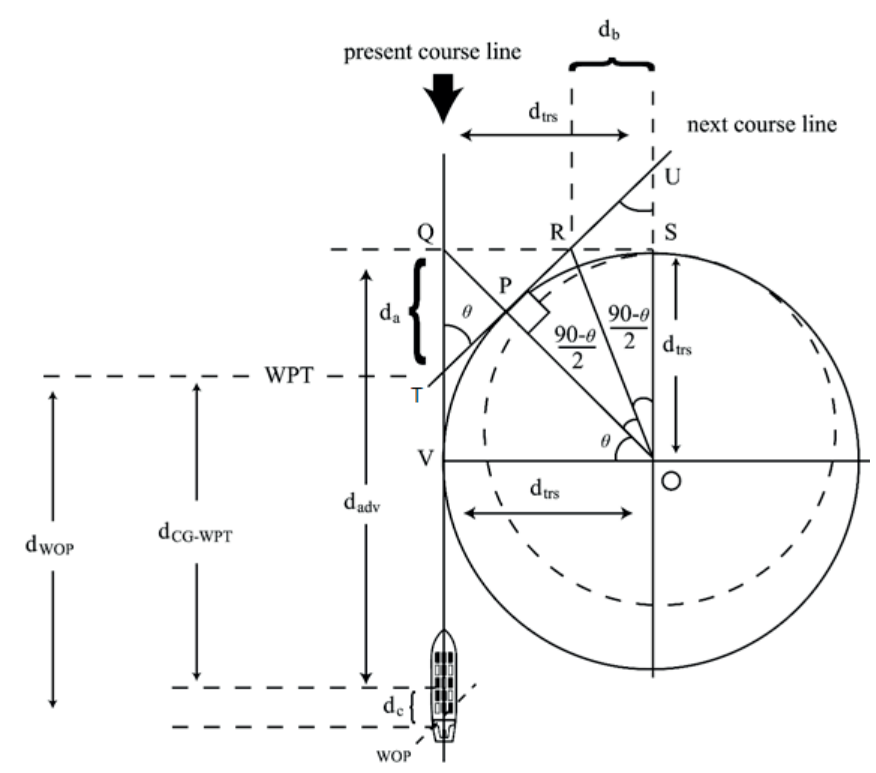

Fig. 11. Distribution details

Because the positioning of the WOP was moved over to WOP', $d_{c}$ was included to represent the distance from the ship's GNSS antenna to its centre of gravity (CG) as shown in Fig. 11. The explanation regarding $d_{c}$ will be further elaborated in a later section. Following this, in addition to the formula in (1), the distance of WOP' from the WPT, also known as $d_{W O P}$, will consist of 1) $d_{C G-W P T}$ and 2) $d_{c}$, hence:

$$
d_{W O P \prime}=d_{C G-W P T}+d_{c}
$$


With reference to the existing ATT formula in (1), $d_{C G-W P T}=d_{a d v}-d_{a}$, the equation can be re-written as:

$$
d_{W O P,}=d_{C G-W P T}+d_{c}
$$

The next step is to find the value of $d_{a}$ and $d_{c}$.

\section{Finding $d_{a}$}

To find $d_{a}$, the following trigonometry function can be used:

$$
\begin{gathered}
\tan \theta=\frac{Q R}{d_{a}} \\
d_{a}=\frac{Q R}{\tan \theta}
\end{gathered}
$$

To get QR, subtract RS from QS. QS is equal to $d_{t r s}$. For now, RS will be represented as $d_{b}$ as shown in Fig. 11. Thus, $Q R=d_{t r s}-d_{b}$. Consequently, (4) can be written as follows:

$$
d_{a}=\frac{d_{t r s}-d_{b}}{\tan \theta}
$$

Finding $d_{b}$

$\triangle \mathrm{ROS}$ is a right-angled triangle; therefore, the value of $d_{b}$ can be obtained by utilising the trigonometry tangent function:

$$
\begin{gathered}
\tan \angle R O S=\frac{d_{b}}{d_{t r s}} \\
d_{b}=d_{\text {trs }} \cdot \tan \angle R O S
\end{gathered}
$$

To determine $\angle$ ROS, first, it needs to be noted that TU is a tangent line to $\mathrm{OP}, \mathrm{TU} \perp \mathrm{OP}$, which makes UPO equal to $90^{\circ}$, $\left\llcorner U P O=90^{\circ}\right.$. According to the triangle rules, a triangle's total inner angle must be equal to $180^{\circ}, \triangle \mathrm{PUO}=180^{\circ}$. The total inner angle of the triangle $\mathrm{PUO}$ is the sum value of $\angle \mathrm{UOP}$, $\llcorner U P O$, and $\angle P U O$. Therefore, it can also be written as:

$$
\begin{gathered}
\angle U O P+\angle U P O+\angle P U O=\triangle P U O \\
\angle U O P+90^{\circ}+\theta=180^{\circ} \\
\angle U O P=180^{\circ}-90^{\circ}-\theta \\
\angle U O P=90^{\circ}-\theta
\end{gathered}
$$

According to the tangent rule to a circle, RP is equal to RS, $|\mathrm{RP}|=|\mathrm{RS}|$, since both distances are tangent to the circle. Thus, the angles of POR and ROS are also the same, $\angle \mathrm{POR}$ $=\angle \mathrm{ROS}$. Subsequently, $\angle R O S$ is half of the value of $\angle P O S$. For this reason, $\angle R O S$ can be expressed as:

$$
\begin{aligned}
& \angle R O S=\angle \frac{P O S}{2} \\
& \angle R O S=\frac{90^{\circ}-\theta}{2}
\end{aligned}
$$

With reference to (6) and the input from (7), the following is obtained:

$$
d_{b}=d_{t r s} \cdot \tan \angle R O S
$$

$$
d_{b}=d_{t r s} \cdot \tan \left(\frac{90^{\circ}-\theta}{2}\right)
$$

Inserting (8) into (5), $d_{a}$ can be obtained as:

$$
d_{a}=\frac{d_{t r s-} d_{t r s} \cdot \tan \left(\frac{90^{\circ}-\theta}{2}\right)}{\tan \theta}
$$

Locating the longitudinal centre of gravity $\mathrm{L}_{\mathrm{CG}}$ and defining $d_{c}$

The centre of gravity or CG is a point where the whole ship's weight is assumed to be concentrated [53]. While navigating, the ship's position will be monitored using the global navigation satellite system (GNSS), located in its wheelhouse. The turning circle is constructed with reference to the ship's CG. The actual course alteration shall be carried out by monitoring the GNSS position by considering when the CG will be at the WOP position. Therefore, the actual WOP' marked on the chart shall include the distance between the bridge, hence $d_{C G}=d_{c}$, and this is applied as follows.

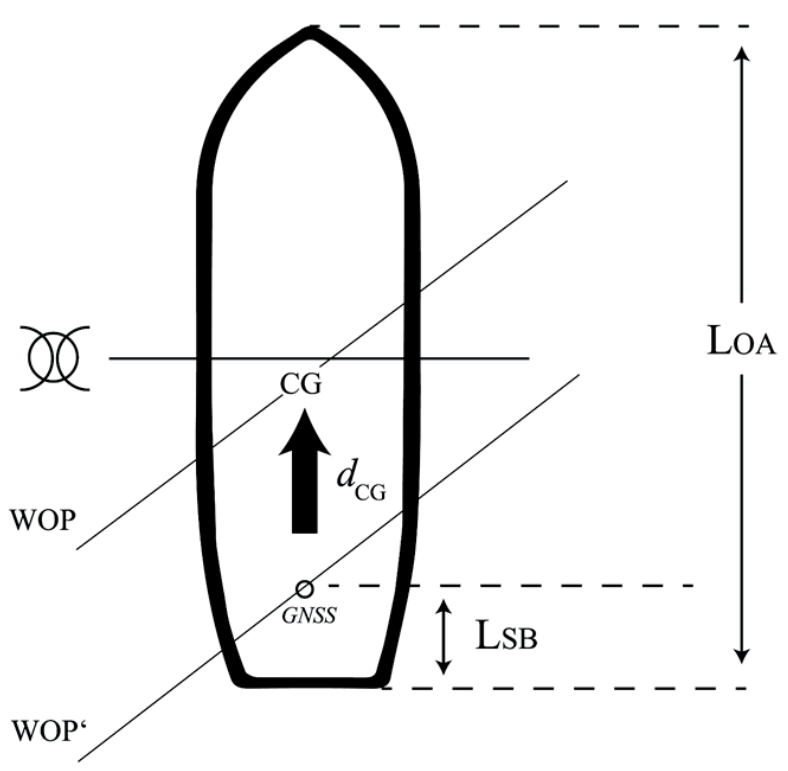

Fig. 12. $d C G$ is the distance between the ship's bridge (LSB) and the ship's longitudinal centre of gravity (LCG)

To determine the $d_{C G}$, firstly, the location of the ship's centre of gravity needs to be confirmed. The longitudinal centre of gravity $\left(L_{C G}\right)$ is equal to the sum of the longitudinal moment divided by the ship's final displacement [53]. Let Xi be the longitudinal distance of the cargo spaces and tanks measured from amidships. W $\dot{t}$ is the amount of weight loaded on each cargo space and tank. As a result, $\sum_{\mathrm{i}} \mathrm{x}_{\mathrm{i}} \mathrm{w}_{\mathrm{i}}$ is the sum of the longitudinal moment exerted on the ship. The formula for a ship's $L_{C G}$ is as follows: 


$$
L_{C G}=\frac{\sum_{i} x_{i} w_{i}}{\Delta}
$$

LOA is the overall length of the ship, and $L_{S B}$ is the length from the ship's stern to the bridge [54]. $L_{C G}$ is measured from the midship, which is half of LOA. The symbol $+L_{C G}$ indicates that the position of $L_{C G}$ is forward of the midship, and $-L_{C G}$ indicates that the position of $L_{C G}$ is at the aft of midship [55]. Therefore, referring to Fig. 12, the $d_{C G}$ can be written as follows:

$$
\begin{gathered}
d_{c}=d_{C G}=\frac{L O A}{2}+L_{C G}-L_{S B} \\
d_{c}=d_{C G}=\frac{L O A}{2}+\frac{\sum_{i} x_{i} w_{i}}{\Delta}-L_{S B}
\end{gathered}
$$

$\mathrm{L}_{\mathrm{CG}}$ can also be obtained directly from the ship's cargo loading computer. Since the difference is very small, $\mathrm{L}_{\mathrm{CG}}$ can also be considered to be equal to the position of the longitudinal centre of buoyancy $\left(\mathrm{L}_{\mathrm{CB}}\right)$, which can be acquired from the ship's stability booklet [54]. In certain cases, the $\mathrm{d}_{c}$ value will be subtracted and represented as - $d_{c}$ if the bridge is located forward of midship, such as for a passenger ship.

In summary, relating to the formula in (3), $d_{W O P}$ can be assembled using the input from (9) and (10) as follows:

$$
\begin{gathered}
d_{W O P \prime}=d_{a d v}-d_{a}+d_{c} \\
d_{W O P^{\prime}}=d_{a d v}-(9)+(10) \\
d_{W O P^{\prime}}=d_{a d v}-\left(\frac{d_{t r s-} d_{t r s} \cdot \tan \left(\frac{90^{\circ}-\theta}{2}\right)}{\tan \theta}\right)+\left(\frac{L O A}{2}+\frac{\sum_{i} x_{i} w_{i}}{\Delta}-L_{S B}\right)
\end{gathered}
$$

The ATMM in (11) was used to find the WOP, which is presented in Table 3 and 4.

\section{VALIDATION AND RESULT}

The Wartsila Ship Simulator meets the challenges of delivering simulation in a modern environment that places a greater focus on flexibility and collaborative learning methods. It has been recognised as a ship simulator that is able to produce simulations which are similar to real navigation applications. The simulator incorporates simulation data based on real-world navigation scenarios, enabling the user to experience a realistic simulation. It complies with the class A - Standard for Certification of Maritime Simulator by DNV-GL (No. DNVGL-ST-0033 April 2018).

A set of charted courses consisting of nine turning angles with a difference of $10^{\circ}$ between each angle was prepared in the simulator. The ATT and ATMM were used to identify the WOP for each course alteration and the results were recorded in Tables 3 and 4 . The ship will follow the prepared courses and turn at the calculated WOP using a maximum rudder angle. The cross-track error of the vessel will be monitored and recorded. The model's effectiveness, which can be determined by comparing the XTD while using the existing model and the proposed mathematical research model, will be tested as follows.

i. Loaded and ballast condition

ii. Port and starboard alteration

iii.Change of course for every $10^{\circ}$.

\section{DATA COLLECTION}

It is important to emphasise again that the research objective is to develop a WOP mathematical model that can bring the ship closer to the charted course by reducing the XTD. Therefore, the manoeuvring simulations were carried out using the ATT and ATMM. The XTD results were recorded during the simulation analysis. The XTD for both methods were compared to see whether the ATMM succeeded in producing a significant improvement or not. The data obtained from the manoeuvring simulation was analysed in three stages. For the first analysis, the data was analysed by comparing the XTD resulting from the ATT and ATMM to the requirements of the XTL as specified by the International Maritime Organisation [7] with the guidance given by Kristić et al. (2020). The XTL was calculated according to the vessel specifications [48]. The XTL used for this study was established using the following formula:

$$
\mathrm{XTL}=\mathrm{d}_{\mathrm{zoc}}+\mathrm{d}_{\mathrm{b}}+\mathrm{d}_{\mathrm{pos}}+\mathrm{d}_{\mathrm{na}}+\mathrm{d}_{\mathrm{so}}(\mathrm{m})
$$

where $d_{z o c}=$ zone of confidence accuracy; $\mathrm{d}_{\text {beam }}=$ half vessel's beam; $d_{\text {pos }}=$ own position accuracy; $\mathrm{d}_{\mathrm{na}}=$ navigational area safety allowance; and $\mathrm{d}_{\mathrm{so}}=(\mathrm{LOA} \times \sin \alpha) / 2$.

Therefore, the XTL for this particular ship was calculated as follows.

Tab. 2. XTL value

\begin{tabular}{|c|c|c|c|c|c|c|}
\hline Area A1 & $\mathrm{d}_{\text {zoc }}$ & $\mathrm{d}_{\text {beam }}$ & $\mathrm{d}_{\text {pos }}$ & $\mathrm{d}_{\text {na }}$ & $\mathrm{d}_{\text {so }}$ & XTL $(\mathrm{m})$ \\
\hline Confined Water & 6.5 & 24.15 & 15 & 50 & 44.7 & 140.4 \\
\hline
\end{tabular}

Throughout the manoeuvring analysis, a total of 72 course alterations were conducted. The manoeuvring analysis was carried out in Kemaman, Malaysia, involving the VLCC tanker. The ship recorded a draught of 9.0 metres in the ballast condition and 16.9 metres while in a fully loaded condition. In this area, the reported water depth ranged from 23.8 to 29.3 metres. Therefore, the depth is more than three times the ship's draught while in the ballast condition and is hence regarded as deep water. While the ship was in fully loaded conditions, the draught-to-depth ratio was less than twice the ship's draught and therefore interpreted as a shallow water area. 


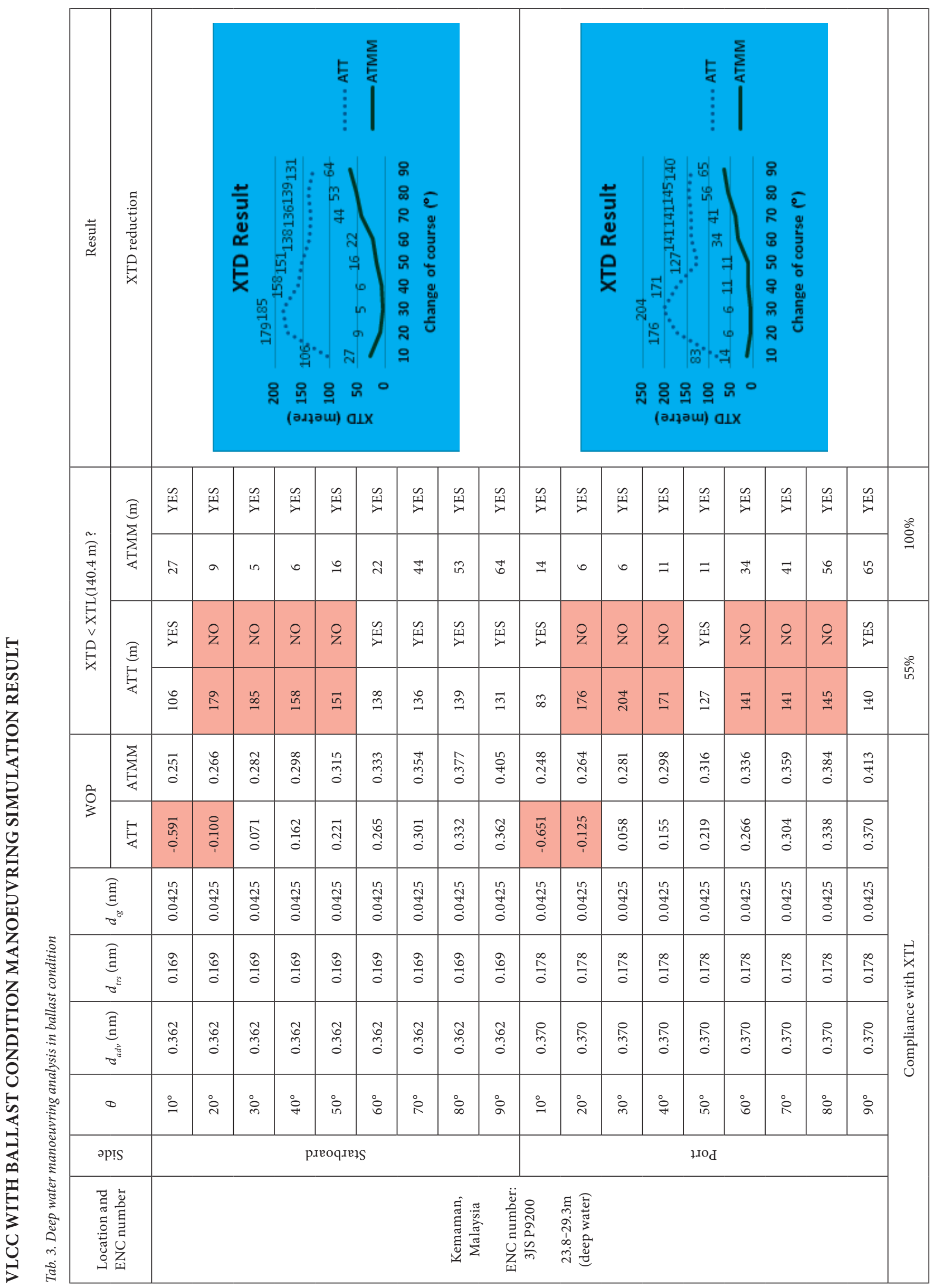




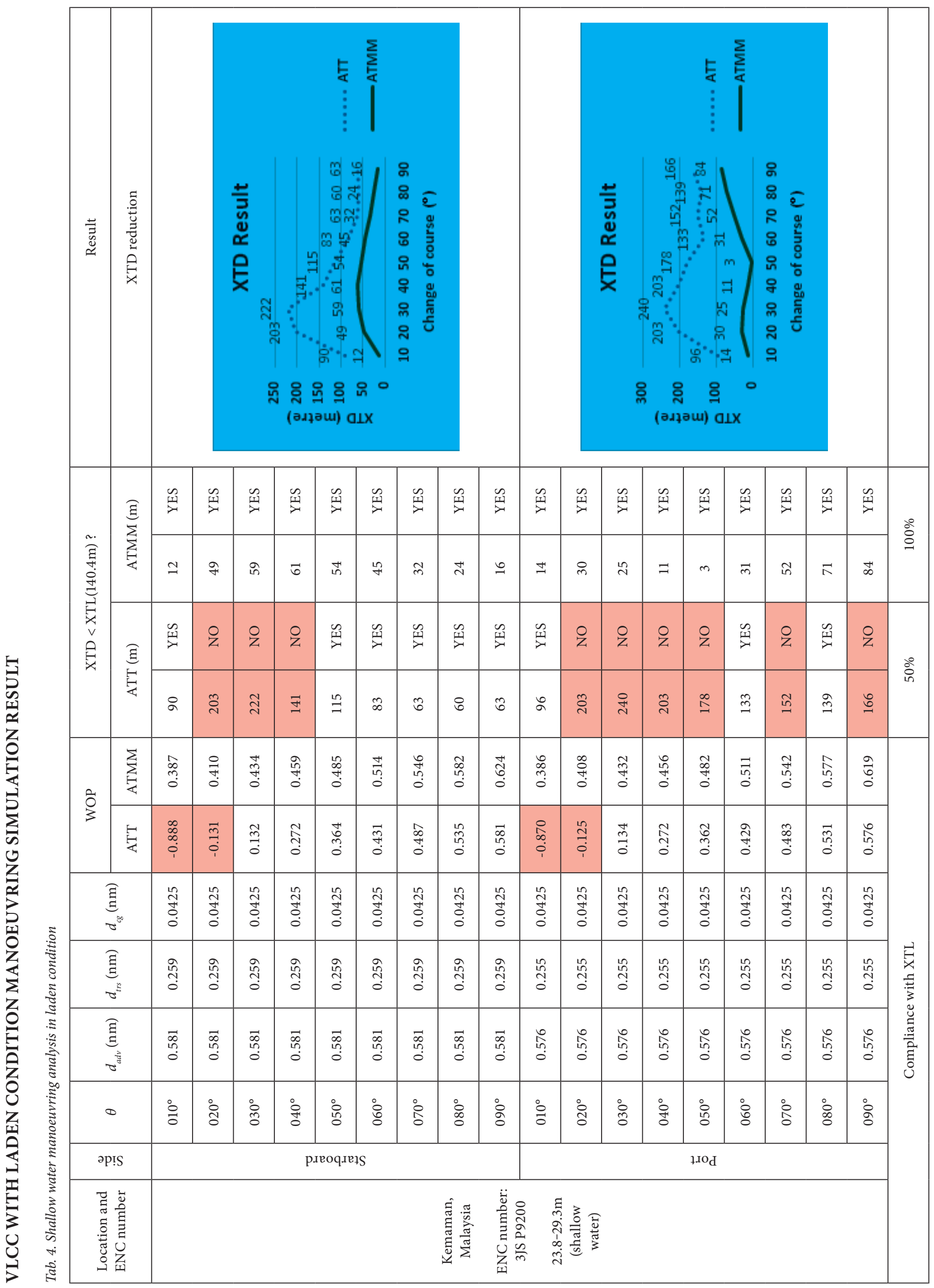




\section{RESULT AND DISCUSSION}

\section{FIRST VALIDATION ANALYSIS - COMPLIANCE WITH}

XTL

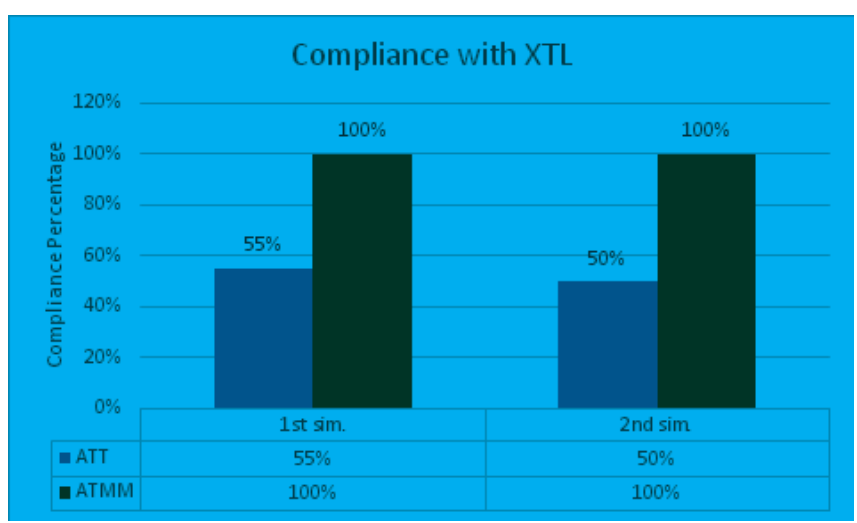

Fig. 13. Compliance with XTL according to simulation
The XTL value used in this research is recommended by IMO and calculated according to the formula proposed by Kristić et al. (2020). The reason for the validation analysis in this stage is to test whether the ATT and ATMM are able to comply with the XTL while carrying out course alteration.

For the first simulation study, while manoeuvring in the ballast condition using the ATT, only 55\% of the turns complied with the XTL. However, when the ship used the ATMM, there was $100 \%$ compliance with the XTL.

During the second simulation study, the same vessel was used, except that the conditions were changed to the fully loaded condition; hence, the water depth was changed to a shallow water area. Using the ATT, the XTL compliance was recorded only at 50\%, compared to manoeuvring using the ATMM, where the compliance with the XTL improved to $100 \%$.

\section{SECOND VALIDATION ANALYSIS - PERCENTAGE CHANGE OF XTD ACCORDING TO CHANGE OF COURSE}

Tab. 5. Percentage change of XTD according to change of course

\begin{tabular}{|c|c|c|c|c|c|c|c|}
\hline \multirow{2}{*}{$\begin{array}{l}\text { Change } \\
\text { of course }\end{array}$} & \multirow{2}{*}{ Condition } & \multirow{2}{*}{ Water depth } & \multirow{2}{*}{ Direction } & \multicolumn{2}{|c|}{ XTD (m) } & \multicolumn{2}{|c|}{ \% Change of XTD } \\
\hline & & & & ATT & АTMM & Individual turn & Average \\
\hline \multirow{4}{*}{$10^{\circ}$} & \multirow{2}{*}{ Ballast } & \multirow{2}{*}{ Deep } & Starboard & 106 & 27 & $-74.5 \%$ & \multirow{4}{*}{$-82.44 \%$} \\
\hline & & & Port & 83 & 14 & $-83.1 \%$ & \\
\hline & \multirow{2}{*}{ Fully Loaded } & \multirow{2}{*}{ Shallow } & Starboard & 90 & 12 & $-86.7 \%$ & \\
\hline & & & Port & 96 & 14 & $-85.4 \%$ & \\
\hline \multirow{4}{*}{$20^{\circ}$} & \multirow{2}{*}{ Ballast } & \multirow{2}{*}{ Deep } & Starboard & 179 & 9 & $-95.0 \%$ & \multirow{4}{*}{$-88.16 \%$} \\
\hline & & & Port & 176 & 6 & $-96.6 \%$ & \\
\hline & \multirow{2}{*}{ Fully Loaded } & \multirow{2}{*}{ Shallow } & Starboard & 203 & 49 & $-75.9 \%$ & \\
\hline & & & Port & 203 & 30 & $-85.2 \%$ & \\
\hline \multirow{4}{*}{$30^{\circ}$} & \multirow{2}{*}{ Ballast } & \multirow{2}{*}{ Deep } & Starboard & 185 & 5 & $-97.3 \%$ & \multirow{4}{*}{$-89.34 \%$} \\
\hline & & & Port & 204 & 6 & $-97.1 \%$ & \\
\hline & \multirow{2}{*}{ Fully Loaded } & \multirow{2}{*}{ Shallow } & Starboard & 222 & 59 & $-73.4 \%$ & \\
\hline & & & Port & 240 & 25 & $-89.6 \%$ & \\
\hline \multirow{4}{*}{$40^{\circ}$} & \multirow{2}{*}{ Ballast } & \multirow{2}{*}{ Deep } & Starboard & 158 & 6 & $-96.2 \%$ & \multirow{4}{*}{$-85.27 \%$} \\
\hline & & & Port & 171 & 11 & $-93.6 \%$ & \\
\hline & \multirow{2}{*}{ Fully Loaded } & \multirow{2}{*}{ Shallow } & Starboard & 141 & 61 & $-56.7 \%$ & \\
\hline & & & Port & 203 & 11 & $-94.6 \%$ & \\
\hline \multirow{4}{*}{$50^{\circ}$} & \multirow{2}{*}{ Ballast } & Deen & Starboard & 151 & 16 & $-89.4 \%$ & \\
\hline & & Deep & Port & 127 & 11 & $-91.3 \%$ & 02020 \\
\hline & Fully Laded & shallow & Starboard & 115 & 54 & $-53.0 \%$ & $-85.05 \%$ \\
\hline & runy Loaded & shanow & Port & 178 & 3 & $-98.3 \%$ & \\
\hline & Dollor & Dorap & Starboard & 138 & 22 & $-84.1 \%$ & \\
\hline & runy Loaded & SHanow & Port & 133 & 31 & $-76.7 \%$ & \\
\hline
\end{tabular}




\begin{tabular}{|c|c|c|c|c|c|c|c|}
\hline \multirow{2}{*}{$\begin{array}{l}\text { Change } \\
\text { of course }\end{array}$} & \multirow{2}{*}{ Condition } & \multirow{2}{*}{ Water depth } & \multirow{2}{*}{ Direction } & \multicolumn{2}{|c|}{ XTD (m) } & \multicolumn{2}{|c|}{ \% Change of XTD } \\
\hline & & & & ATT & ATMM & Individual turn & Average \\
\hline \multirow{4}{*}{$70^{\circ}$} & \multirow{2}{*}{ Ballast } & \multirow{2}{*}{ Deep } & Starboard & 136 & 44 & $-67.6 \%$ & \multirow{4}{*}{$-63.39 \%$} \\
\hline & & & Port & 141 & 41 & $-70.9 \%$ & \\
\hline & \multirow{2}{*}{ Fully Loaded } & \multirow{2}{*}{ Shallow } & Starboard & 63 & 32 & $-49.2 \%$ & \\
\hline & & & Port & 152 & 52 & $-65.8 \%$ & \\
\hline \multirow{4}{*}{$80^{\circ}$} & \multirow{2}{*}{ Ballast } & \multirow{2}{*}{ Deep } & Starboard & 139 & 53 & $-61.9 \%$ & \multirow{4}{*}{$-58.04 \%$} \\
\hline & & & Port & 145 & 56 & $-61.4 \%$ & \\
\hline & \multirow{2}{*}{ Fully Loaded } & \multirow{2}{*}{ Shallow } & Starboard & 60 & 24 & $-60.0 \%$ & \\
\hline & & & Port & 139 & 71 & $-48.9 \%$ & \\
\hline \multirow{4}{*}{$90^{\circ}$} & \multirow{2}{*}{ Ballast } & \multirow{2}{*}{ Deep } & Starboard & 131 & 64 & $-51.1 \%$ & \multirow{4}{*}{$-57.18 \%$} \\
\hline & & & Port & 140 & 65 & $-53.6 \%$ & \\
\hline & \multirow{2}{*}{ Fully Loaded } & \multirow{2}{*}{ Shallow } & Starboard & 63 & 16 & $-74.6 \%$ & \\
\hline & & & Port & 166 & 84 & $-49.4 \%$ & \\
\hline
\end{tabular}

The percentage change was used to identify the value of the reduction of the XTD in terms of percentage when the method in this study is changed from the ATT to the ATMM. For each course alteration angle, the corresponding XTD values are listed in the table. The percentage indicating how much the XTD was reduced for individual turns and the percentage of average reduction are also listed in the table.

The negative value of the percentage change indicated that the XTD was reduced. Hence, a significant reduction of the XTD was recorded during the manoeuvring analysis, when this study changed from the ATT to the ATMM. The series of XTD percentage reductions for every $10^{\circ}$ of course alteration indicated that the ship was manoeuvring closer to the course line. The results showed that while navigating in deep water during ballast conditions, the XTD for course alterations of $10^{\circ}, 20^{\circ}$ and $30^{\circ}$ were reduced by $82.44 \%, 88.16 \%$, and $89.34 \%$, respectively. A similar pattern was observed for course alterations of $40^{\circ}, 50^{\circ}$, and $60^{\circ}$, where reductions of $85.27 \%, 83.03 \%$ and $70.60 \%$ were recorded. Even though the XTD improvements for $70^{\circ}, 80^{\circ}$, and $90^{\circ}$ were not as large as the previous course alterations, reductions of $63.39 \%, 58.04 \%$ and $57.18 \%$ were still recorded.

Now that the study has proved that the ATMM can reduce the $\mathrm{XTD}$, it is crucial to assess whether the two independent sets of data came from the same distribution. To do that, the data were analysed using the Mann-Whitney $\mathrm{U}$ test using IBM SPSS. Adapting the same approaches to this study, the test was used to compare the ATMM model's efficiency with the ATT model.

\section{THIRD VALIDATION ANALYSIS - MANN-WHITNEY U TEST BY MANOEUVRING AREA}

For this study, the null and the two-sided research hypotheses for the nonparametric test are stated as follows: $\mathrm{H}_{0}$ : The distribution of the XTD for the two models is equal $\mathrm{H}_{1}$ : The mean XTD ranks of the two models are not equal If the P-value of the test is less than 0.05 , the null hypothesis $\mathrm{H}_{0}$ will be rejected.

Tab. 6. Mann-Whitney $U$ test by manoeuvring area

\begin{tabular}{|c|c|c|c|c|c|c|c|c|c|}
\hline Test No & $\begin{array}{c}\text { Manoeuvring } \\
\text { description }\end{array}$ & Models & $\mathrm{N}$ & Mean rank & Sum of rank & $\begin{array}{c}\text { Mann- } \\
\text { Whitney U }\end{array}$ & Wilcoxon W & Z & $\begin{array}{c}\text { Asymp. Sig } \\
\text { (2-tailed) } \\
\text { P-value }\end{array}$ \\
\hline \multirow{2}{*}{1} & \multirow{2}{*}{$\begin{array}{c}\text { Ballast } \\
\text { condition, } \\
\text { deep water }\end{array}$} & ATT & 18 & 27.5 & 495 & \multirow{2}{*}{.000} & \multirow{2}{*}{171} & \multirow{2}{*}{-5.127} & \multirow{2}{*}{.000} \\
\hline & & ATMM & 18 & 9.5 & 171 & & & & \\
\hline \multirow{2}{*}{2} & \multirow{2}{*}{$\begin{array}{l}\text { Laden } \\
\text { condition, } \\
\text { shallow } \\
\text { water }\end{array}$} & ATT & 18 & 27.06 & 487 & \multirow{2}{*}{8.000} & \multirow{2}{*}{179} & \multirow{2}{*}{-4.874} & \multirow{2}{*}{.000} \\
\hline & & ATMM & 18 & 9.94 & 179 & & & & \\
\hline
\end{tabular}


Test 1 . The manoeuvring analysis was carried out using a ballast condition bulk carrier in deep water. A Mann-Whitney $\mathrm{U}$ test was then carried out to compare the test scores of the ATT and the ATMM. The test indicated that the difference was statistically significant, where $\mathrm{U}(\mathrm{N}$ ATT $=18, \mathrm{~N}$ ATMM $=18)=.00, \mathrm{z}=-5.127$, and $\mathrm{p}=0.000<0.05$. Therefore, $\mathrm{H}_{0}$ was rejected. The Wilcoxon $\mathrm{W}=171$ indicated that the ATMM had produced a lower value of XTD for the ballast condition in deep water manoeuvring analysis.

Test 2 . The manoeuvring analysis was carried out using a ballast condition bulk carrier in shallow water. Then a MannWhitney U test was run to compare the test scores of the ATT and the ATMM. The test indicated that the difference was statistically significant, where U $(\mathrm{N}$ ATT $=18, \mathrm{~N}$ ATMM $=$ 18) $=8.000, \mathrm{z}=-4.874$, and $\mathrm{p}=0.000<0.05$. Therefore, $\mathrm{H}_{0}$ was rejected. The Wilcoxon $\mathrm{W}=179$ indicated that the ATMM had produced a lower value of XTD for the laden condition in shallow water manoeuvring analysis.

\section{CONCLUSION}

Since route monitoring is one of the important factors for navigation safety, this research focuses on improving track-keeping while changing the ship's course. To maintain the vessel on its intended route when manoeuvring, the WOP must be correctly identified. Route monitoring can be monitored through the development of the XTD. Various methods can be used to observe the XTD; one of them is through the correct applications of the WOP. Therefore, this study was intended to review the ATT and identify how to improve it.

Then, a practical review using a paper and electronic navigation chart was carried out to understand the ATT. During the chart work exercise, two problems were identified. The ATT formula is not ideal for ECDIS installation because it will have difficulty in calculating the WOP for course changes which are less than $20^{\circ}$. Aside from that, the ATT can result in a second overshooting on the expected route, because the final course of the ship is set on $90^{\circ}$, which contradicts another angle of alteration that is less than $90^{\circ}$. Mismatch between the charted course and the actual course while manoeuvring can result in a second overshoot. Following this, an improved mathematical model, namely the ATMM, was developed successfully and verified via manoeuvring analysis using the Wartsila ship simulator.

To validate the XTD data acquired from the simulator, the data wereanalysed in three stages. The purpose of these stages is to satisfy the requirement from the IMO ISM code, which states that any newly developed system shall: 1) Comply with regulations and 2) Provide continuous improvement to the safety management system of the ship.

Therefore, to ensure that the ATMM complies with regulations, the first validation is to ensure that the XTD does not exceed the XTL. The result showed that the XTD corresponding to the ATMM complied $100 \%$ with the XTL.
The second requirement is to ensure that continuous improvement is provided. The improvement was verified through the percentage change of the XTD, where all of the analyses had negative values, thus indicating a reduction of the XTD. After that, the Mann-Whitney U test was carried out to check whether the data from the ATT and ATMM were coming from the same distribution. It can be concluded that the ATMM produced in this study can reduce the XTD. It is also suitable for use on board cargo ships as one of the methods for assessing the WOP, especially during turning in a narrow channel or during pilotage.

\section{CONTRIBUTION OF STUDY}

\section{Mathematical model improvement}

The world is looking forward to the enhancement of navigation safety of autonomous ships [56]. One of the most important aspects of the development of an autonomous ship is the mathematical model and algorithms [57], [58]the human cognitive abilities and the collision avoidance regulations (COLREGs. Nowadays, the integrated bridge and navigation system (IBNS) can greatly enhance route monitoring. The IBNS consists of all available navigation aids, especially the ECDIS. In the ECDIS, the ATMM can be used as an algorithm input. With the vessel manoeuvring details pre-installed in the ECDIS, the ECDIS will automatically produce the WOP for any course changes during passage planning, depending on the vessel states, such as ballast and loaded condition. Even though this research mathematical model contributes to a very small part of the manoeuvring system, it is important that the existing mathematical model or formula which is currently being used should be improved to enhance the safety of navigation for autonomous ships. Hence, since the developed ATMM is proven to be an improved mathematical model that can provide a better course-keeping capability, this research suggests that the ATMM will come in handy as one of the required algorithms which can be used in an autonomous ship's navigation.

\section{Framework for manoeuvring analysis}

This research also suggests a framework for a manoeuvring analysis validation, suggesting that, for any newly developed system, 1) The system shall be validated through its ability to comply with existing regulation, for example the crosstrack limit (XTL); and 2) The system shall be checked for improvement compared to the previous system, for example the improvement of the ATMM over the ATT, which can be observed through the percentage change and validated via the Mann-Whitney U test.

\section{LIMITATIONS OF THE STUDY}

\section{Advance transfer value only for specific conditions}

The advance and transfer distances of a ship are only provided for ballast and fully loaded draft conditions in shallow and deep water. Therefore, if the ship is half or partially loaded, to obtain the advance and transfer distances 
to other drafts, the ship's master needs to carry out his own manoeuvring trial and record the turning circle whenever there is an opportunity to do it. This is because different drafts at different draft-to-water-depth ratios will affect the turning circle of the ship [59].

When the advance and transfer distances are obtained, the WOP for that particular condition can be calculated using the ATMM developed in this study.

\section{Sea condition}

The sea condition used in this study is limited up to Beaufort scale 0-1 only.

\section{SUGGESTION FOR FUTURE RESEARCH}

The ATMM has been proven to provide a better coursekeeping capability. For this reason, the reduction of the XTD will also reduce the distance covered by the ship. Reduction of distance means a reduction of fuel consumption [12], [60]. Perhaps this research can be extended to see the impact of the course-keeping capability on energy efficiency.

It is important to highlight that this research's aim was to improve the ATT. Therefore, the same methodology can be carried out for the CRT and CROT so that all mathematical formulas available are checked and improved if needed, as a preparation towards autonomous ship operations. In addition, while the introduction of the ECDIS has reduced seafarers' dependence on this kind of traditional technique, it is essential to note that not all vessels are equipped with these technologies; therefore, the approach remains helpful for the majority of mariners who sail without them.

The research can also be extended to simulate the difference between the ATT and ATMM in a higher Beaufort force scale.

\section{ACKNOWLEDGEMENT}

This research was supported by the Simulation Department, Akademi Laut Malaysia. This research did not receive any specific grant from funding agencies in the public, commercial, or not-for-profit sectors.

\section{REFERENCES}

1. Y. Wang and G. Tae Yeo, "The Selection of a Foreign Seafarer Supply Country for Korean Flag Vessels," Asian J. Shipp. Logist., vol. 32, no. 4, pp. 221-227, 2016, doi: 10.1016/j. ajsl.2016.12.005.

2. A. S. Kamis, A. F. Ahmad Fuad, M. N. Mohd Fadzil, and S. I. Saadon, "The Impact of Basic Training on Seafarers' Safety Knowledge, Attitude and Behaviour," J. Sustain. Sci. Manag., vol. 15, no. 6, pp. 137-158, Aug. 2020, doi: 10.46754/jbsd.2020.08.012.

3. IMO, "STCW : including 2010 Manila amendments: STCW Convention and STCW Code : International Convention on Standards of Training, Certification and Watchkeeping for Seafarers," 2018. [Online]. Available: http://www. imo.org/en/about/conventions/listofconventions/pages/ international-convention-on-standards-of-training,certification-and-watchkeeping-for-seafarers-(stcw).aspx. [Accessed: 17 Jul. 2018].

4. K. Skora and A. Wolski, "Voyage Planning," Sci. J. Silesian Univ. Technol. Ser. Transp., vol. 92, pp. 123-128, 2016, doi: 10.20858/sjsutst.2016.92.12.

5. D. J. House, "Preventing Collisions at Sea," in Seamanship Techniques, London: Elsevier, 2004, pp. 395-444.

6. Y. Wang, S. Chai, and H. D. Nguyen, "Experimental and numerical study of autopilot using Extended Kalman Filter trained neural networks for surface vessels," Int. J. Nav. Archit. Ocean Eng., vol. 12, pp. 314-324, 2020, doi: 10.1016/j. ijnaoe.2019.11.004.

7. IMO MSC, "Adoption of the Revised Performance Standards for Electronic Chart Display and Information Systems (ECDIS) MSC 82/24/Add.2," 2006.

8. A. M. Lekkas and T. I. Fossen, "Minimization of crosstrack and along-track errors for path tracking of marine underactuated vehicles," 2014 Eur. Control Conf. ECC 2014, no. October 2015, pp. 3004-3010, 2014, doi: 10.1109/ ECC.2014.6862594.

9. S. Vujičić, R. Mohović, and I. Đ. Tomaš, "Methodology for controlling the ship's path during the turn in confined waterways," Pomorstvo, vol. 32, no. 1, pp. 28-35, 2018, doi: 10.31217/p.32.1.2.

10. N. Anwar, Navigation Advanced Mates/Masters, 2nd ed. Weatherby Seamanship International, a Division of Witherbys Publishing Group Limited, 2015.

11. R. E. Reid, "Improvement of Ship Steering Control for Merchant Ships - Phase IIA,” Kings Point, New York, 1978.

12. M. Chaal, "Ship Operational Performance Modelling for Voyage Optimization through Fuel Consumption Minimization," World Maritime University Dissertations, 2018 .

13. R. Lu, O. Turan, E. Boulougouris, C. Banks, and A. Incecik, "A semi-empirical ship operational performance prediction model for voyage optimization towards energy efficient shipping," Ocean Eng., vol. 110, no. July 2014, pp. 18-28, 2015, doi: 10.1016/j.oceaneng.2015.07.042.

14. TAIC, "Final report MO-2016-202: Passenger ship, Azamara Quest, contact with Wheki Rock, Tory Channel, 27 January 2016," no. January, 2016. 
15. MAIB, “MAIB Report No 30/2014 - Navigator Scorpio Less Serious Marine Casualty," 2014.

16. ATSB, "Near grounding of Aquadiva," 2018.

17. T. Takemoto, T. Nomura, H. Yabuki, and K. Inoue, "Characteristics of Pilot's Collision Avoiding Action and Prevention of Marine Collision Accidents," J. Japan Inst. Navig., vol. 124, pp. 47-55, 2011, doi: 10.9749/jin.124.47.

18. USCG, "Lesson from casualties," Proceedings Merch. Mar. Counc., vol. 6, no. 1, 1949.

19. GARD, "Pilot on the bridge - Role, authority and responsibility - GARD,” 2000. [Online]. Available: http:// www.gard.no/web/updates/content/52439/pilot-on-thebridge-role-authority-and-responsibility. [Accessed: 30-Jan-2020].

20. MAIB, "Report on the investigation of the grounding of the Liberian-registered container ship P\&O Nedlloyd Magellan in the Western Approach Channel to Southampton Water on 20 February 2001," Southampton, 2002.

21. ATSB, "Independent investigation into the grounding of the Hong Kong registered products tanker, Atlantic Blue," 2009.

22. TSB, "Marine Investigation Report M14P0014 Grounding Container vessel Cap Blanche Fraser River, British Columbia," Canada, 2014

23. Gard, "Pilotage: A selection of articles previously published by Gard AS," 2014.

24. MAIB, "Faults Pilots for Double Grounding in UAE," 2018. [Online]. Available: https://www.maritime-executive.com/ article/maib-faults-pilots-for-double-grounding-in-uae. [Accessed: 30-Jan-2020].

25. Y. A. Park, T. L. Yip, and H. G. Park, "An Analysis of Pilotage Marine Accidents in Korea," Asian J. Shipp. Logist., vol. 35, no. 1, pp. 49-54, 2019, doi: 10.1016/j.ajsl.2019.03.007.

26. D. Gregory and P. Shanahan, The Human Element: A Guide to Human Behavior in The Shipping Industry. The Stationery Office (TSO), 2010.

27. ICS, Bridge Procedure Guide, Fifth ed. London: Marisec Publications, 2016.

28. MAIB, "Report on the investigation of the grounding and flooding of the ro-ro ferry Commodore Clipper in the approaches to St Peter Port, Guernsey on 14 July 2014," 2015.

29. Steamship Mutual, "The Importance of ECDIS Training and Good Watch-keeping Practices," no. November, pp. $43-45,2014$.
30. IMO, "Guidelines for voyage planning - Resolution A.893(21)," 1999.

31. G. A. Quick, "Master / Pilot Relationship the Role of the Pilot in Risk Management," Group of the International Organisation of Masters, Mates \& Pilots of Maryland. pp. 1-15, 2011.

32. G. Rutkowski, "ECDIS Limitations, Data Reliability, Alarm Management and Safety Settings Recommended for Passage Planning and Route Monitoring on VLCC Tankers," TransNav, Int. J. Mar. Navig. Saf. Sea Transp., vol. 12, no. 3, pp. 483-490, 2018, doi: 10.12716/1001.12.03.06.

33. ISES, "The majority of international fleet now fitted with ECDIS - ISES Association.” [Online]. Available: https:// www.isesassociation.com/the-majority-of-internationalfleet-now-fitted-with-ecdis/. [Accessed: 21 May 2021].

34. IMO, SOLAS Consolidated Edition. London: International Maritime Organization, 2020.

35. Marine Insight, "Understanding Different Types of Manoeuvres of a Vessel," 2019. [Online]. Available: https:// www.marineinsight.com/naval-architecture/differenttypes-of-manoeuvres-of-a-vessel/. [Accessed: 21 May 2021].

36. J. Wu, J. Thorne-Large, and P. Zhang, "Safety first: The risk of over-reliance on technology in navigation," J. Transp. Saf. Secur., pp. 1-28, Apr. 2021, doi: 10.1080/19439962.2021.1909681.

37. K. Aarsæther and T. Moan, "Combined maneuvering analysis, AIS and full-mission simulation," TransNav Int. J. Mar. Navig. Saf. Sea Transp., vol. 1, no. 1, pp. 31-36, 2007.

38. M. J. Van Hilten and P. H. M. Wolkenfelt, "The rate of turn required for geographically fixed turns: A formula and fast-time simulations," J. Navig., vol. 53, no. 1, pp. 146-155, 2000, doi: 10.1017/S0373463399008590.

39. Jithin, "Constant Radius Turn | Knowledge Of Sea," Navigation, 2019. [Online]. Available: https:// knowledgeofsea.com/constant-radius-turn/. [Accessed: 23 Feb 2021].

40. M.-S. Kim, H.-O. Shin, K.-M. Kang, and M.-S. Kim, "Variation of the Turning Circle by the Rudder Angle and the Ship's Speed-Mainly on the Training Ship KAYA-," Bull. Korean Soc. Fish. Technol., vol. 41, no. 2, pp. 156-164, May 2005, doi: 10.3796/KSFT.2005.41.2.156.

41. V. N. Drachev, "Calculating Wheel-Over Point," AsiaPacific J. Mar. Sci., vol. 2, no. 1, pp. 27-46, 2012.

42. IMO, "Standards For Ship Manoeuvrability," London, 2002. 
43. TTEG, "Guidelines on Voluntary Pilotage Services in The Straits of Malacca and Singapore," 2008.

44. ITTC, "Full Scale Measurements Manoeuvrability Full Scale Manoeuvring Trials Procedure,” 2002.

45. E. O. Voit, "Introduction to Mathematical Modeling," in: A First Course in Systems Biology, pp. 19-50, 2020, doi: 10.4324/9780203702260-2.

46. IMO ISM, International Safety Management Code (ISM Code). London: IMO Publishing, 2018.

47. IMO MSC, "Adoption of the Revised Performance Standards for Electronic Chart Display and Information Systems (ECDIS) Msc 82/24/Add.2. MSC Resolution (Vol. 82)." 2006.

48. M. Kristić, S. Žuškin, D. Brčić, and S. Valčić, “Zone of confidence impact on cross track limit determination in ECDIS passage planning," J. Mar. Sci. Eng., vol. 8, no. 8, 2020, doi: 10.3390/JMSE8080566.

49. S. Bansilal, "The application of the percentage change calculation in the context of inflation in Mathematical Literacy," Pythagoras, vol. 38, no. 1, pp. 1-11, 2017, doi: 10.4102/pythagoras.v38i1.314.

50. K. Beck, "How to Calculate Percent Difference," 2020. [Online]. Available: https://sciencing.com/calculatepercent-difference-6331196.html. [Accessed: 20 Dec 2020].

51. N. Nachar, “The Mann-Whitney U: A Test for Assessing Whether Two Independent Samples Come from the Same Distribution," Tutor. Quant. Methods Psychol., vol. 4, no. 1, pp. 13-20, 2008, doi: 10.20982/tqmp.04.1.p013.

52. A. Hart, "Mann-Whitney test is not just a test of medians: differences in spread can be important," BMJ, vol. 323, no. 7309, pp. 391-393, Aug. 2001, doi: 10.1136/bmj.323.7309.391.

53. R. Latorre, "Naval Architecture," in Encyclopedia of Physical Science and Technology, vol. 105, no. 1, Elsevier, 2003, pp. 343-360.

54. A. F. Molland, The Maritime Engineering Reference Book. Elsevier, 2008.

55. P. Mucha, T. Dettmann, V. Ferrari, and O. el Moctar, "Experimental investigation of free-running ship manoeuvers under extreme shallow water conditions," Appl. Ocean Res., vol. 83, no. May 2018, pp. 155-162, 2019, doi: 10.1016/j.apor.2018.09.008.

56. M. G. Jeong, E. B. Lee, M. Lee, and J. Y. Jung, "Multicriteria route planning with risk contour map for smart navigation," Ocean Eng., vol. 172, no. August 2018, pp. 72-85, 2019, doi: 10.1016/j.oceaneng.2018.11.050.

57. T. Statheros, G. Howells, and K. McDonald-Maier, "Autonomous ship collision avoidance navigation concepts, technologies and techniques," J. Navig., vol. 61, no. 1, pp. 129-142, 2008, doi: 10.1017/S037346330700447X.

58. B. Belev, D. Dimitranov, A. Spasov, and A. Ivanov, "Application of information technologies and algorithms in ship passage planning," Cybern. Inf. Technol., vol. 19, no. 1, pp. 190-200, 2019, doi: 10.2478/CAIT-2019-0011.

59. G. Rutkowski, "Determining Ship's Safe Speed and Best Possible Speed for Sea Voyage Legs," TransNav, Int. J. Mar. Navig. Saf. Sea Transp., vol. 10, no. 3, pp. 425-430, 2017, doi: 10.12716/1001.10.03.07.

60. K. Tiwari, K. Hariharan, T. V. Rameesha, and P. Krishnankutty, "Prediction of a research vessel manoeuvring using numerical PMM and free running tests," Ocean Syst. Eng., vol. 10(3), pp. 333-357, 2020, doi: 10.12989/OSE.2020.10.3.333. 


\section{CONTACT WITH THE AUTHORS}

\section{Amir Syawal Kamis}

e-mail:amirsyawal87@gmail.com

Akademi Laut Malaysia,

Bt 30 Kg Tg Dahan, Kuala Sungai Baru, 78200 Melaka,

Malaysia

\section{Ahmad Faizal Ahmad Fuad}

e-mail:faizalfuad75@gmail.com Universiti Malaysia Terengganu,

Kuala Nerus, 21030 Terengganu,

$$
\text { MALAYSIA }
$$

\section{Azmirul Ashaari}

e-mail:azmirul@utm.my

Universiti Teknologi Malaysia, Blok T08, Pusat Pentadbiran UTM, 81310 Johor,

$$
\text { Malaysia }
$$

\section{Che Wan Mohd Noor}

e-mail: che.wan@umt.edu.my Universiti Malaysia Terengganu, Kuala Nerus, 21030 Terengganu,

Malaysia

\section{Sheikh Alif Ali}

e-mail: sheikh_alif@umt.edu.my Universiti Malaysia Terengganu, Kuala Nerus, 21030 Terengganu, MALAYSIA 